\title{
SACRIFÍCIO RITUAL NAS RELIGIÕES AFRO- BRASILEIRAS: REFLEXÕES SOBRE PATRIMONIALIZAÇÃO, MEMÓRIA E ANARQUIVAMENTO
}

\author{
RITUAL SACRIFICE IN AFRO-BRAZILIAN RELIGIONS: \\ REFLECTIONS ON PATRIMONIALIZATION, MEMORY \\ AND UNARCHIVED
}

\author{
Clovis Carvalho Britto ${ }^{a}$ \\ Kellen Josephine Muniz de Limab
}

\begin{abstract}
RESUMO
Introdução: Este artigo investiga como o sacrifício ritual de animais constitui um lugar de memória das religiões afro-brasileiras e as tensões que surgem no campo das políticas do patrimônio. Objetivo: Como desdobramento da problemática, tenta compreender as ressonâncias envolvidas nesse universo simbólico e a teia de elementos que parece sustentar a estratégia de esquecimento das políticas culturais em relação a esse saber-fazer tradicional. Metodologia: Partindo de uma breve análise do processo de registro do ofício das baianas de acarajé, é traçado um comparativo a fim de tentar compreender os elementos que interferem, direta ou indiretamente, na eleição do que é digno de ser rememorado e ocupar o lugar de patrimônio cultural que, em última escala, representa a própria identidade nacional. Resultados: Argumenta que embora o sacrifício ritual seja um lugar de memória das religiões afro-brasileiras, o esvaziamento da sua importância enquanto bem cultural e saber tradicional está diretamente relacionado a ressonância externa negativa dessa prática, consequência do que Yvonne Maggie chamou de "medo do feitiço", que povoa o imaginário popular e acompanha as religiões afro-brasileiras ainda nos dias atuais. Conclusões: Evidencia o modo como as tensões contribuem para a instituição de "memórias anarquivadas" no campo das políticas patrimoniais brasileiras e as profícuas intersecções entre a ciência da informação e o campo do patrimônio cultural.
\end{abstract}

Descritores: Sacrifício Ritual. Religiões Afro-Brasileiras. Memória. Patrimônio cultural.

a Doutor em Sociologia pela Universidade de Brasília e em Museologia pela Universidade Lusófona de Humanidades e Tecnologias, Lisboa. Professor da Faculdade de Ciência da Informação da Universidade de Brasília (UnB). E-mail: clovisbritto@unb.br

${ }^{b}$ Mestre em Direitos Humanos pela Universidade Tiradentes. Especialista em Direito Civil e Processual Civil. Professora da Universidade Tiradentes (UNIT). E-mail: kellen_muniz@yahoo.com.br 


\section{INTRODUÇÃO}

O sacrifício ritual de animais nas religiões afro-brasileiras constitui um fundamento, ou mesmo um dogma interno. A partir dele são acionadas memórias coletivas, mitos ancestrais e um universo simbólico diretamente relacionado com a cosmovisão e identidade da comunidade religiosa, promovendo o fortalecimento de laços afetivos e de pertencimento. Trata-se, desse modo, de um bem passível de patrimonialização, ou seja, de ser reconhecido pela política pública como um documento/monumento, nos moldes definidos por Le Goff (2003), uma construção repleta de interesses que projeta uma imposição voluntária ou involuntária de futuro: "[...] resultado de uma montagem, consciente ou inconsciente, da história, da época, da sociedade que o produziram, mas também das épocas sucessivas durante as quais continuou a viver, talvez esquecido, durante as quais continuou a ser manipulado, ainda que pelo silêncio" (p. 537-538).

Neste sentido, o presente artigo discute o papel do sacrifício ritual enquanto um lugar de memória para as religiões afro-brasileiras, bem como sua posição de bem cultural e saber-fazer que compõe um conjunto de marcas identitárias da cozinha votiva de terreiro. A partir dessa dupla elaboração se pretende compreender como o não reconhecimento (ou não valorização) do sacrifício ritual como um lugar de memória, como um saber-fazer, por meio das políticas culturais, constitui uma estratégia de silenciamento e anarquivamento.

Nesse aspecto, o trabalho apresenta as características específicas do sacrifício ritual de animais nas religiões afro-brasileiras e a importância dessa ritualística enquanto componente de sistema alimentar sagrado que fortalece os laços entre homens e deuses. Em meio a essa discussão, evidencia o sacrifício ritual enquanto lugar de memória e analisa o processo de registro do ofício das baianas de acarajé no intuito de estabelecer um comparativo a fim de compreender os elementos que interferem, direta ou indiretamente, no processo de negociação do que é digno de ser rememorado e ocupar o lugar de patrimônio cultural que, em última escala, representaria a identidade nacional. Por fim, inicia uma discussão sobre a relação entre a ressonância negativa do sacrifício ritual 
e as tentativas de esvaziamento da sua importância enquanto bem cultural e saber tradicional.

Essa discussão em torno daquilo que Maria Cecília Londres Fonseca (2005) designou de "patrimônio não consagrado", vinculado ao esquecimento que a política federal de patrimônio no Brasil destinava majoritariamente à cultura popular, às matrizes indígenas, afro-brasileiras e imigracionistas, contribui para uma outra problematização sobre as interfaces entre a Ciência da Informação e o campo do Patrimônio. Willian Souza e Giulia Crippa (2010), ao efetuarem um mapeamento das pesquisas sobre o patrimônio no campo da Ciência da Informação, concluem que os trabalhos existentes demonstram um itinerário profícuo quando o campo entende o patrimônio cultural como um documento, como uma fonte de informação. Destacam, do mesmo modo, que a Museologia foi a principal responsável pela inserção dessa discussão. Portanto, este trabalho realiza uma aproximação inicial que pretende discutir os efeitos da patrimonialização ou do "arquivamento" de determinados documentos no rol dos bens reconhecidos como representativos da nação e, especialmente, as negociações, as reverberações e os protocolos de leitura em torno dos bens "anarquivados".

\section{AJEUM COMO LUGAR DE MEMÓRIA?}

O candomblé, religião de matriz africana, possui no sacrifício religioso de animais um importante pilar do culto às suas divindades. Trata-se de um fundamento religioso, um símbolo milenar de suas crenças (ROBERT, 2008).

Tadvald (2007) esclarece que o sacrifício religioso do animal oferecido às divindades está cercado de uma série de cuidados. Em se tratando de um presente sagrado ofertado às divindades, é necessário que o animal esteja saudável e que o sacrifício não lhe imponha sofrimentos (antes ou durante o procedimento ritual).

Esse fundamento religioso do candomblé está diretamente relacionado ao seu sistema alimentar, pois nem todas as partes do animal sacrificado (ou 
sacralizado) serão ofertadas, grande parcela da carne será compartilhada e consumida pelos próprios integrantes da comunidade religiosa (LODY, 2012; TADVALD, 2007). O ato de compartilhar e consumir os mesmos alimentos oferecidos às divindades é comum no candomblé e tem fundamental importância Segundo entendem os fiéis, trata-se do Ajeum ${ }^{1}$, que renova e fortalece os laços sagrados que unem deuses e homens (LODY, 2012). A comida funciona como elo dessa comunhão ou aliança divina. Como ensina Fernández-Armesto (2004, p. 30) "a maioria das sociedades tem hábitos alimentares que pertencem à esfera do sagrado: existem substâncias que consumimos para nos tornar sagrados ou íntimos dos deuses ou dos espíritos".

A maior parte da carne do animal sacrificado é consumida pela comunidade de fiéis, como forma de comunhão entre deuses e homens. $O$ destino final da carne do animal sacrificado é virar comida, alimento dos homens e dos deuses, através do qual vínculos são estabelecidos, laços de comunhão e sociabilidade são fortalecidos. No terreiro se alimenta o corpo e a alma, comese além da boca:

Comer além da boca é uma ampliação sobre o conceito de comer nas religiões afro-brasileiras. Tudo está na permanente lembrança e ação de que tudo come. Come o chão, come o ixé, come a cumeeira, come a porta, come o portão, comem os assentamentos, árvores; enfim, comer é contatar e estabelecer vínculos fundamentais com a existência da vida, do axé, dos princípios ancestrais e religiosos do terreiro (LODY, 2012, p. 27).

Para além do que se come, Maciel (2001) também destaca a importância do como (técnicas relacionadas ao modo de fazer), quando (ocasiões e celebrações especiais) e com quem (valor que envolve partilha e comensalidade) se come. Da reunião de todos esses aspectos resulta o que a autora chama de "sistemas alimentares" ou "cozinhas"2, o que engloba técnicas, maneiras de fazer, hábitos, restrições, e uma série de elementos e comportamentos que vão muito além do simples ato de ingerir um alimento (MACIEL, 2001). Alimentar-se

\footnotetext{
1 Palavra yorubá que designa o ato de comer.

2 "Práticas alimentares diversificadas que compreendem não apenas certos itens alimentares consumidos mais frequentemente, mas sim um conjunto de alimentos que relacionam-se às representações coletivas, ao imaginário social, às crenças do grupo enfim, a suas práticas culturais." (MACIEL, 2001, p. 150).
}

Inf. Inf., Londrina, v. 24, n. 3, p. 433 - 451, set./dez. 2019. 
constitui também um ato cultural e social, carregado de valores e símbolos de pertencimento e identificação que conduzem a uma rede de sociabilidade e de significados próprios (MACIEL, 2004).

Lody (2012) indica que o ajeum nos terreiros é dos mais significativos momentos da socialização pela comida, pois tanto o fiel quanto o visitante não religioso comungam e partilham do mesmo alimento fortalecendo as relações entre homens e deuses. Comer, neste sentido, "equivale a viver, a manter, a ter, a preservar, a iniciar, a comunicar, a reforçar memórias individuais e coletivas" (LODY, 2012, p. 29). De modo semelhante, Maciel indica que "a comida envolve emoção, trabalha com a memória e com sentimentos" (MACIEL, 2001, p. 151).

Em se tratando de comida votiva, portanto, são acionadas memórias e sentimentos relacionados a ancestralidade mítica e a cosmovisão específica da comunidade religiosa em questão. Seguindo esse raciocínio e pensando no sacrifício ritual como uma técnica inserida em um sistema alimentar específico, em outras palavras, um saber-fazer próprio da cozinha afrorreligiosa, do qual resulta boa parte da comida votiva que alimentará deuses e fiéis, é possível identificar no sacrifício ritual um lugar de memória.

Segundo Pierre Nora, os lugares de memória produziram um novo tipo de memória, a memória-arquivo: "nascem e vivem do sentimento que não há memória espontânea, que é preciso criar arquivos, organizar celebrações, manter aniversários, pronunciar elogios fúnebres, notariar atas, porque estas operações não são naturais". (1993, p. 13). Além disso, trata-se de uma forma de ritualização da memória em um determinado espaço: "só é lugar de memória se a imaginação o investe de uma aura simbólica [...] só entra na categoria se for objeto de um ritual". (p. 21)

Para Pollak (1989, p.10), "a memória consiste em uma operação coletiva dos acontecimentos e das interpretações do passado que se quer salvaguardar, através de tentativas de definição e reforço de sentimentos de pertencimento [...]". Ela consiste, pois, em um trabalho de reconstrução narrativa seletiva do passado pautada em critérios de inclusão e exclusão acionados por quem revive a memória, "ressignificando as noções de tempo e espaço e selecionando o que vai e o que não vai ser dito" (GOMES, 1996, p. 21). 
Desta forma, dos critérios de seletividade acionados no trabalho de rememoração resulta também um esquecimento intencional das outras possibilidades narrativas que aquela memória poderia incorporar, portanto, a memória nunca é neutra (HUYSSEN, 2014, p. 158, 181). Neste sentido, ela sempre é acionada para corroborar o discurso de quem rememora ou se intitula guardião daquela memória acionada:

A memória é sempre um passado presente, o passado comemorado e produzido no presente, que inclui, de forma invariável, pontos cegos evasões. A memória, portanto, nunca é neutra. Tal como a própria historiografia, por mais objetiva que pretenda ser, toda lembrança está sujeita a interesses e usos funcionais específicos. (HUYSSEN, 2014, p. 181)

Assim, o trabalho de rememoração coletiva envolve uma esfera de negociação e conflitos entre memórias individuais e do grupo, a partir do qual são estabelecidas as tensões entre o que deve ser preservado/enaltecido no discurso da memória e o que deve ser apagado/esquecido (GOMES, 1996). Mas não se olvida da importância que a memória tem para a manutenção da coesão social, cultural e identitária de um grupo, afinal, como assinala Huyssen (2014, p. 157) “[...] uma sociedade sem memória é um anátema".

A memória coletiva, portanto, na tentativa de definir o que é comum ao grupo, o que decorre de um trabalho que envolve tensões e negociações internas que, embora crie hierarquizações e silenciamentos de memórias individuais, funciona como importante fator aglutinador de identidades e sentimentos de pertencimento. E se, por um lado, nenhum grupo social tem sua imortalidade assegurada, por outro, sua memória coletiva pode sobreviver e ter continuidade através de mitos que se alimentam de referências culturais, literárias ou religiosas (POLLAK, 1989).

É justamente em mitos, através dos quais a memória coletiva do grupo é revivida, fortalecida e transmitida, que a cosmovisão religiosa de matriz africana está fundamentada. Sua concepção de tempo é cíclica ${ }^{3}$ e "se acredita que a vida

\footnotetext{
3 "O tempo cíclico é o tempo da natureza, o tempo reversível, e também o tempo da memória, que não se perde, mas se repõe. O tempo da história, em contrapartida, é o tempo irreversível, um tempo que não se liga nem à eternidade, nem ao eterno retorno. $O$ tempo do mito e o tempo
}

Inf. Inf., Londrina, v. 24, n. 3, p. 433 - 451, set./dez. 2019. 
é uma eterna repetição do que já aconteceu num passado remoto narrado pelo mito" (PRANDI, 2001, p. 43). É no passado, revivido pelos mitos e preservado pela memória, que se encontram as respostas para os enigmas e percalços do tempo presente (OLIVEIRA, 2012).

Que o terreiro representa um lugar de memória para as religiões afrobrasileiras não é mais novidade. Retratado por Sodré (2002) como a principal forma social negro-brasileira, o terreiro representa historicamente uma forma de resistência cultural e de coesão social. Foi nos terreiros que os diversos grupos étnicos, identificados de modo geral como "Nagô"4, conseguiram preservar suas raízes culturais (além de religiosas) e conservar um profundo sentido de comunidade (SANTOS, 1976), reconstruindo uma cosmovisão singular de mundo, centrada em valores como a ancestralidade, integração/solidariedade e respeito pela diversidade.

Mas para além do espaço físico, ou seja, da cultura material a que se reconhece essa qualidade de ancorador de uma memória coletiva, os sentimentos de pertencimento que promovem a coesão social da comunidade afetiva em questão também podem ser acionados a partir de uma memória ancorada em uma referência simbólica imaterial, por exemplo, um modo de fazer através do qual mitos são revividos e transmitidos oralmente dentro daquela comunidade. É o que ocorre com o sacrifício ritual.

O sacrifício ritual de animais (ou imolação, ou matança, ou ainda, sacralização) constitui um fundamento das religiões afro-brasileiras. Está alicerçado em uma atmosfera de segredo acessível apenas a alguns membros internos, e cujo aprendizado é transmitido oralmente dos mais velhos para os

da memória descrevem um mesmo movimento de reposição: sai do presente, vai para o passado e volta ao presente - não há futuro" (PRANDI, 2001 p. 49).

4 Juana Elbein dos Santos (1976) explica que "Nagô" era o nome genérico através do qual eram conhecidos no Brasil os grupos étnicos provenientes do Sul e do Centro do Daomé e do Sudeste da Nigéria, de uma região que se convencionou chamar Yoru baland. Esses grupos trouxeram para o Brasil "seus costumes, suas estruturas hierárquicas, seus conceitos filosóficos e estéticos, sua língua, sua música, sua literatura oral e mitológica. E, sobretudo, trouxeram para o Brasil sua religião" (SANTOS, 1976, p. 29). 
mais novos ${ }^{5}$. Por meio dos saberes presentes no fazer do sacrifício ritual, os mais velhos, "guardiões da memória" (GOMES, 1996), revivem os mitos de seus ancestrais, reforçam sentimentos de identidade, pertencimento e afetividade, e cuidam da preservação e transmissão das memórias por ele acionadas. Como não reconhecer, portanto, no sacrifício ritual das religiões afro-brasileiras um lugar de memória? Além de lugar de memória, as técnicas envolvidas no sacrifício ritual afrorreligioso constituem uma marca identitária desse sistema alimentar, ou seja, da cozinha votiva de terreiro, o que faz desse fundamento religioso uma referência cultural e um saber-fazer ${ }^{6}$.

Chegando a este ponto é preciso tentar compreender como o não reconhecimento (ou não valorização) do sacrifício ritual como um lugar de memória, como um saber-fazer, por meio das políticas culturais na representação da nação, constitui uma estratégia de silenciamento e de anarquivamento.

Afinal, para além das memórias coletivas ancoradas nesse saber-fazer, quais são as ressonâncias externas por ele acionadas? E o que isso tem a ver (em maior ou menor grau), por exemplo, com o que fez do acarajé um bem cultural reconhecido em detrimento de tantas outras referências identitárias da religiosidade afro-brasileira? Em outras palavras: o que faz do ofício das baianas do acarajé um lugar de memória enaltecido e preservado, alçado ao patamar de patrimônio cultural imaterial, e do sacrifício ritual um lugar de silenciamento/anarquivamento?

\footnotetext{
${ }^{5}$ Rabelo (2015) explica que o processo de aprendizado no candomblé se assemelha ao trabalho de juntar folhas, em virtude da fragmentação que se opera. Parte do conhecimento religioso "é considerado secreto (fundamento) e mantido fora do alcance não só dos de fora, mas também daqueles, de dentro, que se situam na base da hierarquia religiosa" (RABELO, 2015, p. 238).

${ }^{6}$ Rabelo (2015) traz uma breve descrição de uma das muitas nuances presentes nesse saberfazer. Trata-se do que a autora chama de composição em camadas: "a arrumação dos materiais usados nas oferendas segue um modo de composição similar. As partes dos bichos sacrificados destinadas aos orixás são depositadas em um alguidar e parcialmente recobertas seja com uma espessa camada de penas, seja com materiais como milho branco, arroz, ou feijão, também ofertados. Em alguns casos flores são "plantadas" sobre a base de grãos cozidos." (RABELO, 2015, p. 243).
} 


\section{PATRIMONIALIZAÇÃO E ANARQUIVAMENTOS: DE VOLTA À NEGOCIAÇÃO E CONFLITO}

A oferenda de comidas de santo (ou votivas) nos terreiros evolve uma série de rituais específicos que fazem a correspondência entre cada comida e o respectivo Orixá (Inquice ou Vodum, a depender da nação de origem a que o terreiro está filiado). É o que ocorre quando são oferecidos acarajé para lansã, por exemplo. Neste sentido, o modo de fazer o acarajé, assim como outras técnicas próprias da cozinha afrorreligiosa, ressalta os saberes e as práticas tradicionais enraizados no cotidiano das comunidades religiosas afro-brasileiras que são passíveis de patrimonialização.

O Decreto-Lei n $3.551 / 00$, que instituiu o Registro dos Bens Culturais de Natureza Imaterial, foi responsável por tornar aplicável o artigo 216 da Constituição Federal ao prever o registro dos bens culturais imateriais efetuado pelo IPHAN. De acordo com o artigo $1^{\circ}$ do Decreto, o registro do patrimônio imaterial poderá ser efetuado em quatro livros de registro: o dos Saberes; o das Celebrações; o das Formas de Expressão; e o dos Lugares. O Livro dos Saberes visa registrar os conhecimentos e modos de fazer enraizados no cotidiano das comunidades tradicionais. O Livro das Celebrações visa assegurar o registro dos rituais e festejos que promovem "a vivência coletiva do trabalho, da religiosidade, do entretenimento" e de outras manifestações coletivas existentes na vida social. O Livro das Formas de Expressão visa documentar as manifestações artísticas (literatura, dança, música, artes plásticas e cênicas etc.) de certa comunidade ou que encarnem a identidade nacional. Finalmente, o Livro dos Lugares visa registrar espaços onde se concentram e reproduzem práticas culturais coletivas, a exemplo de mercados, feiras, santuários, praças etc. (SANTANA; OLIVEIRA, 2005, p.1).

Em 2007, o IPHAN publicou o Dossiê relativo ao registro do ofício das baianas de acarajé como patrimônio cultural do Brasil, no Livro dos Saberes, promovendo o reconhecimento da herança cultural africana no processo de formação da sociedade brasileira. Reconhecido como um bem cultural símbolo de identidade étnica, regional e religiosa, o acarajé, comida votiva até então 
preparada exclusivamente nos terreiros por meio de técnicas ritualizadas, ganhou as ruas transferindo para os tabuleiros heranças simbólicas da religiosidade afro-brasileira. Neste sentido, o registro deste ofício no Livro dos Saberes constituiu uma importante ferramenta para manutenção e promoção da transmissão dos saberes relacionados ao bem cultural em questão (BRASIL, 2007).

Dentre os rituais que compõem a oferendas de comida para as divindades (a exemplo do acarajé) encontramos, não raramente, o sacrifício de animais, importante componente desse sistema culinário que agrega técnicas relacionadas às tradições africanas, formando um conjunto de saberes e práticas culturais coletivas que são transmitidos oralmente dos mais velhos para os mais jovens, segundo uma hierarquia religiosa:

Há sentido e função em cada ingrediente, e há significados nas quantidades, nos procedimentos, nos atos das oferendas, nos horários especiais e dias próprios, no som de cânticos, de toques de atabaque, agogô, cabaça e adjá ou do paô - bater palmas seguindo ritmos específicos. (LODY, 2012, p. 29)

Assim como o ofício das baianas de acarajé aciona todo um sistema simbólico diretamente relacionado à memória da sua comunidade de pertencimento (no caso, as religiões afro-brasileiras), o que dá suporte histórico e cultural a esse marcador identitário da culinária de terreiro, também o sacrifício ritual aciona, entre os membros do grupo de pertencimento, esse mesmo universo mítico-simbólico, o que faz dele um lugar de memória. Ao que parece, entretanto, enquanto o acarajé foi "promovido" ao posto de bem cultural e importante referência identitária reconhecida como patrimônio cultural brasileiro, parece passar longe a ideia do sacrifício ritual como um bem cultural também passível de registro e consequente proteção.

Algumas perguntas podem, então, ser suscitadas a partir dessa hipótese: como se dá o processo de passagem de uma memória (ou lugar de memória) para uma referência cultural, um símbolo de uma nação? Que agenciamentos estão envolvidos nesse processo de patrimonialização/arquivamento? Quais silenciamentos são produzidos a partir dessa dinâmica? Que tipo de negociação deslocou o ofício das baianas de acarajé do lugar ocupado por um saber 
tradicional afrorreligioso para o lugar de patrimônio cultural imaterial? Ou, o que fez do ofício das baianas de acarajé uma referência cultural em detrimento de tantas outras marcas identitárias da religiosidade afro-brasileira, a exemplo do sacrifício ritual?

Para ser registrado no Livro dos Saberes o ofício das baianas de acarajé precisou ser reconhecido não apenas como um importante símbolo cultural, mas como um Saber:

Os Saberes são conhecimentos tradicionais associados a atividades desenvolvidas por atores sociais reconhecidos como grandes conhecedores de técnicas, ofícios e matérias-primas que identifiquem um grupo social ou uma localidade. Geralmente, estão associados à produção de objetos e/ou prestação de serviços que podem ter sentidos práticos ou rituais. Trata-se da apreensão dos saberes e dos modos de fazer relacionados à cultura, memória e identidade de grupos sociais. (BRASIL, 2014, p. 1).

Decorre daí mais uma pergunta: o saber tradicional materializado no sacrifício ritual se encaixa na descrição normativa do que vem a ser os "saberes"? Em caso positivo, qual seria a razão do não-reconhecimento dessa emblemática referência identitária da religiosidade de matriz africana enquanto patrimônio cultural imaterial? Quais elementos estão inseridos nesse processo de anarquivamento/silenciamento?

Aqui dialogamos com a ideia de patrimonialização enquanto um arquivamento de um bem no livro respectivo, estabelecendo um rol fruto de um gesto jurídico-político. Do mesmo modo, aqueles bens culturais não patrimonializados foram nomeados como "anarquivados", utilizando o conceito de Constância Duarte (2009) para se referir as estratégias que retiram determinados indivíduos ou expressões da memória nacional:

A constituição de novos arquivos - novas memórias - se configurou então em uma experiência ímpar: iniciávamos a busca sem saber o que seria encontrado; e para interpretar obras desconhecidas e reconstruir histórias de vida, impôs-se o desafio de realizar leituras com múltipla perspectiva - que envolvessem gênero, história das mentalidades e história cultural; que dessem conta de alterar marcos do sistema literário; e ainda fornecessem novos instrumentos de análise. $E$ logo estávamos todas dominadas pelo "mal de arquivo" (en mal d'archive, expressão também cunhada por Derrida), ou seja, 
dedicadas apaixonadamente a restaurar o arquivo justo onde ele escapa, justo onde algo se anarquiva, ou seja, intuir o que não se inclui na listagem, a ausência da memória. (DUARTE, 2009, p. 15)

No campo do patrimônio, Abreu (2015, p. 67) explica que a patrimonialização de um bem revela um processo de escolha em que são eleitos símbolos capazes de "representar metaforicamente a ideia abstrata de nação e seus corolários, como a ideia de humanidade". Neste sentido, a patrimonialização sacraliza aquele determinado bem que passa a ser digno de representar uma sociedade ou uma cultura, ao passo que relega ao esquecimento (ou silenciamento) diversos outros candidatos a símbolos culturais nacionais. Portanto, dizer o que pode ser eleito como patrimônio material ou imaterial significa determinar o que é digno (ou indigno) de representar a nação.

Foi o que se viu quando do processo de tombamento do terreiro Casa Branca, em que se formou um embate ideológico em torno de decidir o que poderia ser valorizado e consagrado através da política de tombamento, o que significava dizer, em última escala, o que era digno de representar a identidade nacional:

[...] o tombamento de Casa Branca significava a afirmação de uma visão da sociedade brasileira como multiétnica, constituída e caracterizada pelo pluralismo sociocultural. Não há dúvida de que tal medida de reconhecimento do Estado representava também uma reparação às perseguições e à intolerância manifestadas durante séculos pelas elites e pelas autoridades brasileiras contra as crenças e os rituais afro-brasileiros (VELHO, 2006, p. 240).

Neste contexto, entender as diferenças simbólicas existentes entre o ofício do acarajé e o fundamento do sacrifício ritual talvez passe pelos tipos de ressonâncias externas provocadas por ambos. Se de um lado temos uma ressonância externa positiva do acarajé, que o incorporou como "comida típica" e símbolo nacional de orgulho (assim como vemos com a feijoada), a ressonância externa provocada pelo sacrifício ritual parece remeter ao que Maggie (1992) chamou de "medo do feitiço", uma espécie de "medo infantil" que "ninguém esquece [...] ao ver vela, galinha preta, pele de cobra seca, alguidar 
com farofa, panos vermelhos e pretos, garrafas de cachaça na esquina de casa" (MAGGIE, 1992, p. 21).

Especialmente o sacrifício religioso de animais parece ter sido associado ao "medo do feitiço" de tal modo que esse fundamento religioso encontra forte ressonância externa negativa. Daí talvez decorra o seu silenciamento e mesmo a tentativa de esquecimento que o acompanha, sendo, portanto, pelo menos por hora, difícil imaginá-lo sendo consagrado como um patrimônio cultural imaterial, embora se adeque perfeitamente à categoria de "saber" trazida pelo IPHAN.

Se por um lado é bem possível que a ressonância externa positiva tenha favorecido o processo de reconhecimento e registro do ofício das baianas de acarajé como patrimônio cultural imaterial, por outro, de modo antagônico, a ressonância externa negativa do sacrifício ritual (materializada no "medo do feitiço") parece ser um importante elemento que interfere diretamente no não reconhecimento/valorização dessa prática pelas políticas culturais, do que decorre uma estratégia de esquecimento e esvaziamento da sua importância enquanto lugar de memória.

Todavia, o campo do patrimônio é constituído por atravessamentos de poder, fator que produz outras estratégias de arquivamento/anarquivamento. Nesse aspecto vale a pena destacar que uma das primeiras coleções reconhecidas como patrimônio cultural brasileiro consiste na Coleção Museu de Magia Negra do Museu da Polícia Civil do Rio de Janeiro. Apesar de ser o primeiro tombamento etnográfico do país, inscrito no Livro do Tombo Arqueológico, Etnográfico e Paisagístico em 1938, passou décadas silenciado, conforme destacou Alexandre Correa (2005, p. 408): "esse processo de patrimonialização de objetos e peças de magia negra durante muitas décadas foi "relegado" ao esquecimento pelo próprio Instituto do Patrimônio, que relutava em reconhecer qualquer valor patrimonial nesse acervo considerado "bizarro"”.

Assim como acontece com a memória, essa estratégia de anarquivamento perpassa por uma trama de agenciamentos e escolhas do que é digno de ser rememorado como representativo da cultura brasileira, e o que deve ser apagado, silenciado. Isso nos remete a lição de Huyssen (2014, p. 158) de que "o esquecimento precisa ser situado num campo de termos e fenômenos 
como silêncio, desarticulação, evasão, apagamento, desgaste, repressão todos os quais revelam um espectro de estratégias tão complexo quanto o da própria memória".

\section{CONSIDERAÇÕES FINAIS}

A prática do sacrifício ritual de animais, também denominada sacralização ou imolação, constitui um elemento fundamental das religiões afro-brasileiras. Mais do que "apenas" uma liturgia, por meio do sacrifício ritual, os mais velhos, guardiões da memória, revivem os mitos de seus ancestrais, reforçam sentimentos de identidade, pertencimento e afetividade, e cuidam da preservação e transmissão das memórias por ele acionadas. Portanto, além de lugar de memória, as técnicas envolvidas no sacrifício ritual afrorreligioso constituem uma marca identitária desse sistema alimentar, ou seja, da cozinha votiva de terreiro, o que faz desse fundamento religioso uma referência cultural e um saber-fazer.

Entretanto, o que se vê é um não-reconhecimento dessa referência identitária da religiosidade de matriz africana enquanto patrimônio cultural imaterial, o que remete a um processo de silenciamento e esquecimento. Sabese que a patrimonialização sacraliza determinados bens que passam a ser dignos de representar uma sociedade ou uma cultura, ao passo que relega ao esquecimento (ou silenciamento) diversos outros candidatos a símbolos culturais nacionais. Portanto, eleger o que pode ser eleito como patrimônio material ou imaterial significa determinar o que é digno (ou indigno) de representar a nação.

Neste contexto, é importante compreender a relação que existe entre o tipo de ressonância externa provocada pelo sacrifício ritual e a produção de esquecimento das políticas culturais em relação a este bem cultural. Assim, os estudos da literatura nos remetem ao que Maggie (1992) chamou de "medo do feitiço" como um elemento importante para a compreensão sobre a ressonância negativa que o sacrifício ritual de animais encontra na sociedade. 
Ao que parece, essa ressonância impacta e interfere diretamente na produção de silenciamento e anarquivamento que acompanha e marca o sacrifício ritual, de modo a parecer improvável que o mesmo venha a ser consagrado como um patrimônio cultural imaterial, embora se adeque perfeitamente à categoria de "saber" trazida pelo IPHAN. Do mesmo modo, mesmo se reconhecido, as lutas simbólicas podem promover seu anarquivamento, nos moldes ocorridos com o primeiro patrimônio etnográfico brasileiro (CORREA, 2005). Além disso, é fundamental problematizar os protocolos de arquivamento, no caso das políticas patrimoniais brasileiras. Conforme sublinhou Regina Abreu (2012), quando analisou o que designou de efeitos inesperados da "patrimonialização das diferenças", algumas questões merecem ser consideradas, a exemplo da introdução de uma nova forma de registro pelas agências internacionais e nacionais, desconhecidas das comunidades tradicionais; das tensões em torno da propriedade intelectual e do direito coletivo; e da dificuldade de reconhecer a dimensão nacional de determinadas culturas.

$\mathrm{Na}$ verdade, nosso intuito foi promover algumas reflexões iniciais sobre as políticas de patrimonialização, memória e anarquivamento visando apontar itinerários para pesquisas que interseccionem a Ciência da Informação e o campo do Patrimônio, especialmente os chamados "patrimônios nãoconsagrados", sublinhando, assim, os limites e os embates em torno dessa categoria.

\section{REFERÊNCIAS}

ABREU, Regina. Patrimônio: ampliação do conceito e processos de patrimonialização. In: CURY, Marília Xavier; VASCONCELLOS, Camilo de Mello; ORTIZ, Joana Montero (Orgs.). Questões indígenas e museus: debates e possibilidades. São Paulo: MAE/USP; Secretaria de Estado da Cultura, 2012.

ABREU, Regina. Patrimonialização das diferenças e os novos sujeitos de direito coletivo no Brasil. In: TARDY, Cécile (dir.); DODEBEI, Vera (Orgs.). Memória e novos patrimônios. Marseille: OpenEdition Press, 2015. 
BRASIL. Ofício das baianas de acarajé. Brasília: Instituto do Patrimônio Histórico e Artístico Nacional, 2007.

BRASIL. Livros de registro. Brasília: Instituto do Patrimônio Histórico e Artístico Nacional, 2014.

CORREA, Alexandre Fernandes. A Coleção Museu de Magia Negra do Rio de Janeiro: o primeiro patrimônio etnográfico do Brasil. Mneme, Revista de Humaniades, Caicó, v. 7, n. 18, p. 404-438, out./nov. 2005.

DUARTE, Constância Lima. Arquivos de mulheres e mulheres anarquivadas: histórias de uma história mal contata. Gênero, Niterói, v. 9, n. 2, p. 11-17, 1. sem. 2009.

DURKHEIM, Émile. As Formas Elementares da Vida Religiosa. São Paulo: Martins Fontes, 2014.

FERNÁNDEZ-ARMESTO, Felipe. Comida: uma história. Tradução de Vera Joscelyn. Rio de Janeiro: Record, 2004.

FONSECA, Maria Cecília Londres. 0 patrimônio em processo: trajetória da política federal de preservação no Brasil. 2. ed. Rio de Janeiro: UFRJ/MinCIPHAN, 2005, 295p.

GOMES, Ângela de Castro. A guardiã da memória. Acervo - Revista do Arquivo Nacional, Rio de Janeiro, v. 9, n. 1/2, p.17-30, jan./dez. 1996.

HUYSSEN, Andreas. Culturas do passado-presente: modernismos, artes visuais, políticas da memória. Tradução Vera Ribeiro. Rio de Janeiro: Contraponto: Museu de Arte do Rio, 2014.

LE GOFF, Jacques. História e memória. Campinas: Editora Unicamp, 2003.

LODY, Raul. Santo também come. 2. ed. Rio de Janeiro: Pallas, 2012.

MACIEL, Maria Eunice. Cultura e alimentação ou o que têm a ver os macaquinhos de Koshima com Brillat-Savarin? Horizontes Antropológicos, Porto Alegre, vol. 7, n. 16, p. 145-156, dez. 2001.

MACIEL, Maria Eunice. Uma cozinha à brasileira. Estudos Históricos, Rio de Janeiro, n. 33, p. 25-39, jan.-jun. 2004.

MAGGIE, Yvonne. Medo do feitiço: relações entre magia e poder no Brasil. Rio de Janeiro: Arquivo Nacional, 1992.

NORA, Pierre. Entre memória e história: a problemática dos lugares. Projeto História, São Paulo: PUC-SP, n. 10, 1993. 
OLIVEIRA, Eduardo David de. Filosofia da ancestralidade como filosofia africana: Educação e cultura afrobrasileira. Revista Sul-Americana de Filosofia e Educação, n.18, p. 28-47, 2012.

POLLAK, Michael. Memória, esquecimento, silêncio. Tradução de Dora Rocha Flaksman. Estudos Históricos, Rio de Janeiro, v. 2, n. 3, 1989, p. 3-15.

PRANDI, Reginaldo. O candomblé e o tempo: concepções de tempo, saber e autoridade da África para as religiões afro-brasileiras. Revista Brasileira de Ciências Sociais [online]. V.16, n.47, p. 43-58. 2001.

RABELO, Miriam C. M. Aprender a ver no candomblé. Horizontes Antropológicos, Porto Alegre, v. 21, n. 44, p. 229-251, jul./dez. 2015.

ROBERT, Yannick Yves Andrade. Sacrifício de animais em rituais de religiões de matriz africana Anais do XVI Seminário de Iniciação Científica. Pontifícia Universidade Católica do Rio de Janeiro, Rio de Janeiro, 2008.

SANTANA, Luciano Rocha; OLIVEIRA, Thiago Pires. O patrimônio cultural imaterial das populações tradicionais e sua tutela pelo Direito Ambiental. Jus Navigandi, Teresina, v. 10, n. 750, 24 jul. 2005. Disponível em: http://jus.com.br/artigos/7044. Acesso em: 15 ago. 2016.

SANTOS, Juana Elbein dos. Os Nàgô e a morte: Pàdè, Àsèsè e o culto Égun na Bahia. Traduzido pela Universidade Federal da Bahia. Petrópolis: Vozes, 1976.

SODRÉ, Muniz. O Terreiro e a cidade: a forma social negro-brasileira. Salvador: Secretaria da Cultura e Turismo; Imago, 2002. (Bahia: Prosa e poesia).

SOUZA, Willian Eduardo Righini de. CRIPPA, Giulia. O campo da Ciência da Informação e o patrimônio cultural: reflexões iniciais para novas discussões sobre os limites da área. Enc. Bibli: R. Eletr. Bibliotecon. Ci. Inf., Florianópolis, v. 15, n. 29, p. 1-23, 2010.

TADVALD, Marcelo. Direito litúrgico, direito legal: a polêmica em torno do sacrifício ritual de animais nas religiões afro-gaúchas. Revista Caminhos, Goiana, v. 5, n. 1, p. 129-147, jan./jun. 2007.

VELHO, Gilberto. Patrimônio, negociação e conflito. Mana, v. 12, n. 1, 2006.

\section{RITUAL SACRIFICE IN AFRO-BRAZILIAN RELIGIONS: REFLECTIONS ON PATRIMONIALIZATION, MEMORY AND UNARCHIVED}

\section{ABSTRACT}


Introduction: This paper investigates how the ritual sacrifice of animals constitutes a place of memory of the Afro-Brazilian religions and the tensions that arise in the field of patrimony politics. Objective: As an unfolding of the problematic, it tries to understand the resonances involved in this symbolic universe and the web of elements that seems to support the strategy of forgetting cultural policies in relation to this traditional knowhow. Methodology: Starting from a brief analysis of the process of registration of the office of the Bahians of Acarajé, a comparative is drawn in order to try to understand the elements that interfere, directly or indirectly, in the election of what is worthy of being remembered and occupy the place of cultural patrimony which, in the last scale, represents the national identity itself. Results: It argues that although ritual sacrifice is a place of memory for Afro-Brazilian religions, the emptying of its importance as a cultural good and traditional knowledge is directly related to the negative external resonance of this practice, a consequence of what Yvonne Maggie called "fear of the spell", which populate the popular imagination and accompany the Afro-Brazilian religions still today. Conclusions: It shows how tensions contribute to the institution of "unarchived memories" in the field of Brazilian patrimonial policies and the fruitful intersections between information science and the field of cultural heritage.

Descriptors: Ritual Sacrifice. Afro-Brazilian Religions. Memory. Cultural heritage.

\title{
SACRIFICIO RITUAL EN LAS RELIGIONES AFRO- BRASILEÑAS: REFLEXIONES SOBRE PATRIMONIALIZACIÓN, MEMORIA Y SIN ARCHIVE
}

\begin{abstract}
RESUMEN
Introducción: Este artículo investiga cómo el sacrificio ritual de animales constituye un lugar de memoria de las religiones afrobrasileñas y las tensiones que surgen en el campo de las políticas del patrimonio. Objetivo: Como desdoblamiento de la problemática, intenta comprender las resonancias involucradas en ese universo simbólico y la red de elementos que parece sostener la estrategia de olvido de las políticas culturales en relación a ese saber hacer tradicional. Metodología: A partir de un breve análisis del proceso de registro del oficio de las baianas de acarajé, se traza un comparativo a fin de intentar comprender los elementos que interfieren, directa o indirectamente, en la elección de lo que es digno de ser rememorado y ocupar el lugar de patrimonio cultural que, en última instancia, representa la propia identidad nacional. Resultados: Argumenta que aunque el sacrificio ritual es un lugar de memoria de las religiones afrobrasileñas, el vaciamiento de su importancia como bien cultural y el saber tradicional está directamente relacionado con la resonancia externa negativa de esa práctica, consecuencia de lo que Yvonne Maggie llamó "miedo al hechizo", que puebla el imaginario popular y acompaña a las religiones afro-brasileñas aún en los días actuales. Conclusiones: Evidencia el modo en que las tensiones contribuyen a la institución de "memorias anarquivadas" en el campo de las políticas patrimoniales brasileñas y las fructíferas intersecciones entre la ciencia de la información y el campo del patrimonio cultural.
\end{abstract}


Clovis Carvalho Britto, Kellen Josephine Muniz de Lima

Sacrifício ritual nas religiões afro-brasileiras: reflexões sobre patrimonialização, memória e anarquivamento

Descriptores: Sacrificio Ritual. Religiones Afro-Brasileñas. Memoria. Patrimonio cultural.

Inf. Inf., Londrina, v. 24, n. 3, p. 433 - 451, set./dez. 2019. 